\title{
SOME FEATURES OF TEXTURE FORMATION UNDER ZONE MELTING OF $\mathrm{Bi}_{2} \mathrm{Sr}_{2} \mathrm{Ca}_{1} \mathrm{Cu}_{2} \mathrm{O}_{\mathrm{y}}$ CERAMICS
}

\author{
T. D. AKSENOVA, P. V. BRATUKHIN AND S. V. SHAVKIN \\ Moscow Engineering Physics Institute, Kashirskoe sh. 31, Moscow 115409, Russia
}

A. O. KOMAROV AND S. A. VORONKOV

Moscow Institute of Steel and Alloys, Leninskiy pr., Moscow 117936, Russia

(Received 5 November 1993; in final form 18 March 1994)

\begin{abstract}
The crystallographic texture of a zone melted $\mathrm{Bi}_{2} \mathrm{Sr}_{2} \mathrm{Ca}_{1} \mathrm{Cu}_{2} \mathrm{O}_{\mathrm{y}}$ high temperature superconductor was studied by $\mathrm{X}$-ray diffraction technique. Semi-quatitative methods were suggested for texture estimation in this material. Some texture parameters were revealed to describe the texture state of the samples and to define their superconducting transport properties. A mechanism of the texture formation under zone melting treatment of the samples and some features of the texture were discussed.
\end{abstract}

KEY WORDS: Crystallographic texture, high temperature superconductor, zone-melting solidification, texture formation mechanism.

\section{INTRODUCTION}

High field generation with superconducting magnets operating at liquid helium temperature is one of the important potential application of high temperature superconductors (HTSC). To create practicable magnets it is necessary to obtain HTSC wires with critical current density up to $10^{5} \mathrm{~A} / \mathrm{cm}^{2}$, but weak links between grains restrict critical current densities in this material ${ }^{1}$. So a high degree of crystallographic texture is a necessary condition for achieving high critical current capacity of HTSC. Zonemelting solidification is one of the most promising ceramic methods because of its high texturing ability ${ }^{2}$. A systematic texture study was carried out to determine the features of texture formation in zone melted $\mathrm{Bi}_{2} \mathrm{Sr}_{2} \mathrm{Ca}_{1} \mathrm{Cu}_{2} \mathrm{O}_{\mathrm{y}}$ ceramics.

\section{EXPERIMENTAL}

$\mathrm{Bi}_{2} \mathrm{O}_{3}, \mathrm{CaCO}_{3}, \mathrm{SrCO}_{3}$ and $\mathrm{CuO}$ oxides in appropriate proportions were ground calcined and melted $\left(T \sim 1200^{\circ} \mathrm{C}\right)$ with followed rapid cooling $\left(\sim 10^{3} \mathrm{~K} / \mathrm{c}\right)$. Obtained rods $2 \mathrm{~mm}$ in diameter contain an amorphous phase with small crystallites of $\mathrm{Bi}_{2} \mathrm{Sr}_{2} \mathrm{Cu}_{1} \mathrm{O}_{\mathrm{x}}$ (2201 phase) and $\mathrm{Bi}_{2} \mathrm{Sr}_{2} \mathrm{Ca}_{1} \mathrm{Cu}_{2} \mathrm{O}_{\mathrm{y}}(2212$ phase). The gradient temperature treatments have been 
made by two methods: with a sharp focus monoelement heater ( $G$-series) and by noncrucible zone melting in air (Z-series).

The monoelement heater with a shapr focus allows to process a material at peak zone temperature from $750^{\circ}$ to $855^{\circ} \mathrm{C}$. The temperature gradient was $20 \mathrm{~K} / \mathrm{mm}$. The rods were drawn through the gradient region with a velocity of $8 \mathrm{~mm} / \mathrm{h}$. The temperature was maintained constant with $2 \mathrm{~K}$ accuracy.

The temperature control was not maintained during noncrucible zone melting with light heating. Drawing velocity was varied from 2.4 to $2.4 \mathrm{~mm} / \mathrm{h}$.

Some sample were heat treated at $815^{\circ} \mathrm{C}$ for $100 \mathrm{hr}$ after melting. The gradient and zone melting techniques were described in detail elsewhere ${ }^{3}$. All the melting conditions and phase composition are available in Table 1.

\section{PROCEDURES}

X-ray diffraction analysis was carried out with the standard powder diffractometer DRON-3 (Co-K $\mathrm{K}_{\alpha}$ radiation) with texture attachment. X-ray spectra were registered in step scan mode (steps of 0.02-0.05 degrees) and were refined by the procedure described $\mathrm{in}^{4}$, which eliminates the instrumental aberrations. Both transverse and longitudinal cross sections ( $T$ and $L$ ) of the samples were XRD investigated (Figure 1).

Semi-quantitative phase analysis was carried out. Integral intensities of diffraction lines (115) of 2212 and 2201 phases were determined to calculate relative 2212 and

Table 1 Samples preparation conditions.

\begin{tabular}{|c|c|c|c|c|}
\hline Sample & $\begin{array}{c}\text { Maximum zone } \\
\text { temperature, } \\
{ }^{\circ} \mathrm{C}\end{array}$ & $\begin{array}{c}\text { Zone moving } \\
\text { rate, } \\
\mathrm{mm} / \mathrm{h}\end{array}$ & $\begin{array}{c}\text { Temperature } \\
\text { treatment } \\
\text { (in air), }{ }^{\circ} \mathrm{C} / \mathrm{h}\end{array}$ & $\begin{array}{c}\text { Relative } 2212 \\
\text { phase content, } \\
\%\end{array}$ \\
\hline & $G$-series & Gradient & Temperature & Treatment \\
\hline$G 16$ & 800 & 8 & - & 35 \\
\hline$G 24$ & 815 & 8 & - & 80 \\
\hline$G 23$ & 825 & 8 & - & 75 \\
\hline$G 22$ & 835 & 8 & - & 40 \\
\hline$G 20$ & 845 & 8 & - & 40 \\
\hline$G 21$ & 855 & 8 & - & 40 \\
\hline$G 26$ & 830 & 8 & $815 / 100$ & 60 \\
\hline$G 27$ & 825 & 8 & $815 / 100$ & 95 \\
\hline \multirow[t]{2}{*}{$G 28$} & 750 & 8 & $815 / 100$ & 95 \\
\hline & Z-series & Zone & Temperature & Treatment \\
\hline$Z 27$ & - & 5 & - & 30 \\
\hline$Z 20$ & - & 9 & - & 5 \\
\hline$Z 25$ & - & 11 & - & 5 \\
\hline$Z 28$ & - & 11 & $815 / 100$ & 80 \\
\hline$Z 29$ & - & 17 & $815 / 100$ & 95 \\
\hline$Z 30$ & - & 24 & $815 / 100$ & 85 \\
\hline$Z 31$ & - & 30 & $815 / 100$ & 85 \\
\hline$Z 21$ & - & 2.4 & $820 / 10$ & 80 \\
\hline$Z 10$ & - & 10 & $820 / 30$ & 90 \\
\hline$Z 7$ & - & 11 & $820 / 50$ & 85 \\
\hline
\end{tabular}



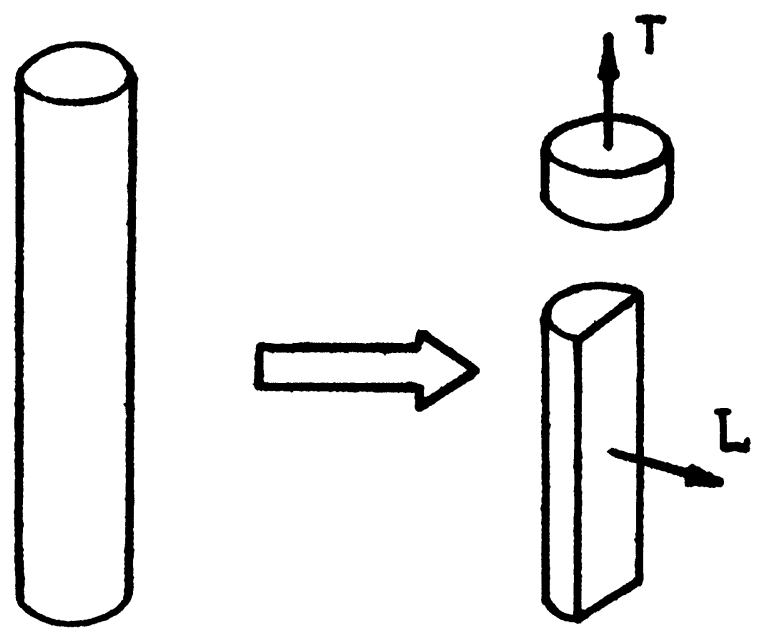

Figure 1 A scheme of sample preparation for X-ray experiments.

2201 phase content. These lines have strong intensities and weak texture sensitivity (its poles are far from texture pole (001) and (100)), so we can suppose that the relative content of 2212 phase is given by equation:

$$
V^{2212}=1-\left\{\frac{P^{\exp }}{P^{\text {theor }}}+1\right\}^{-1},
$$

where $P^{\text {exp }}=\left\{\frac{\left.\right|_{2212} ^{115}}{I_{2201}^{115}}\right\}^{\text {exp }}-$ measured intensity ratio;

$$
P^{\text {theor }}=\left\{\frac{\left.\right|_{2212} ^{115}}{I_{2201}^{115}}\right\}^{\text {theor }} \text { - calculated intensity ratio. }
$$

It is necessary to note that (1) defines only the relative content of 2212 and 2201 phase in crystalline form, while the amorphous phase is not subjected to the abovementioned analysis. Phase content data are presented in Table 1; its errors are connected with registration accuracy of line integral intensity (5-10\%).

\section{TEXTURE ANALYSIS}

A low crystal lattice symmetry of Bi phases (tetragonal or orthorhombic) causes the splitting and overlapping of observed XRD lines. So conventional texture procedures are rather hard to use. Usually used methods of a tape texture description (such as simple comparison of $\mathrm{X}$-ray spectra of $\mathrm{Bi}$ ceramic samples, or the texture degree estimation by the ratio of the integrated strength of (001) peaks $(I=4-10)$ to that of whole peaks in the X-ray diffraction pattern of the phase ${ }^{5}$, or by $F=1-I_{(115)} /$ $I_{(0010)} / I_{o(115)} / I_{o(0010)}{ }^{6}$ can't be used for the samples, prepared by zone-melting solidification technique, because their texture differs from a tape textures. 
$\mathrm{X}$-ray spectra were used as a first approach for the texture estimation of the samples under discussion. The X-ray spectra for $T$ and $L$ cross-sections of $G 27$ and Z28 samples are shown in the Figure 2. X-ray line intensities of the sample G27 are similar for both cross sections and almost correspond to calculated line intensities while much higher (200) and (220) intensities are obvious in $T$ cross section of sample Z28. It indicates texture difference of the samples.

The integral intensity of diffraction lines can be used for fast texture analysis. This approach permits to define a texture parameter and its tendencies for series of samples in dependence on their manufacturing parameters. It is necessary to note that only relative (not absolute) intensities are needed for the elimination of geometry factors and spectrum registration errors. As bench mark lines we used (008), (200), (220) reflections (corresponding to possible texture maximum) and (117) as the least sensitive to texture changes because its pole is far enough away from (001), (100), (110) poles $\left(\sim 40-60^{\circ}\right)$ (see Figure 4).

Ratios of (200), (220) and (008) to (117) allow to distinguish the presence of a definite texture maximum and to observe the texture changes. The texture coefficient $K_{t}$ was calculated as follows:

$$
K_{t}=\left(I_{H K L} / I_{117}\right)^{\exp } /\left(I_{H K L} / I_{117}\right)^{\text {theor }} \text {, }
$$

where $\left(I_{H K L} / I_{117}\right)^{\text {exp }}$ - measured intensity ratio;

$\left(I_{H K L} / I_{117}\right)^{\text {theor }}$ - calculated intensity ratio.

The dependence of $K_{t}$ upon the peak temperature $T$ of gradient melting is shown in Figure 3. It is obvious that texture formation begins at temperatures above $840^{\circ} \mathrm{C}$. The textures of zone melted samples are sufficiently greater then those of gradient melted samples. So $K_{t}=14$ corresponds to sample Z20. It witnesses for higher temperature of zone melting.

Inverse pole figures (IPE) should be used for a texture qualitative characterization. IPF were built by routine method from integral intensities (we used Morrison normalization technique ${ }^{7}$ ). They show the crystallographic normal distribution parallel to different external axes. IPF for samples the $G 26$ abd Z28 are plotted in Figure 4 .

IPF can show the texture evolution under changing zone/gradient melting conditions. Unfortunately, exact texture data are not available from these IPF because of the low accuracy of the integral intensity determination. Thus intensity of the lines in the center of IPF (such as (313), (315)) has relative errors of 30-60\% because of their weak intensities and overlapping with neighbor lines. Nevertheless the IPF let to describe qualitatively the texture forming in the studied samples. One can see from Figure 4 that normals to (HK0) planes for the samples with strong texture Z28 and G26 mainly coincide with the rode axis, hence normals to (001) planes mainly lay in the direction perpendicular to the zone axis.

For study of predominant spatial orientation of (001) plane normals the direct pole figures (DPF) (001) were registered. Registration of DPF was carried out by tilting technique ${ }^{7}$. It is natural to use the half width of the texture maximum $\beta_{t}$ as a texture estimation parameter. $\beta_{t}$ is determined in the center of texture maximum (angle range $20^{\circ}$ ). So defocusing effects are not noticeable in so narrow angle range and no correction for untextured sample was made to aviod supplementary mistakes.

DPF (001) of samples $Z 7$ and $Z 21$ were registered on the (0010) reflection of the 2212 phase at $2 \theta=33.8^{\circ}$. This reflection is partially overlapped by 2201 phase lines (008) $-2 \theta=33.45^{\circ}$, and $(115)-2 \theta=34.51^{\circ}$. However presence of these lines can 

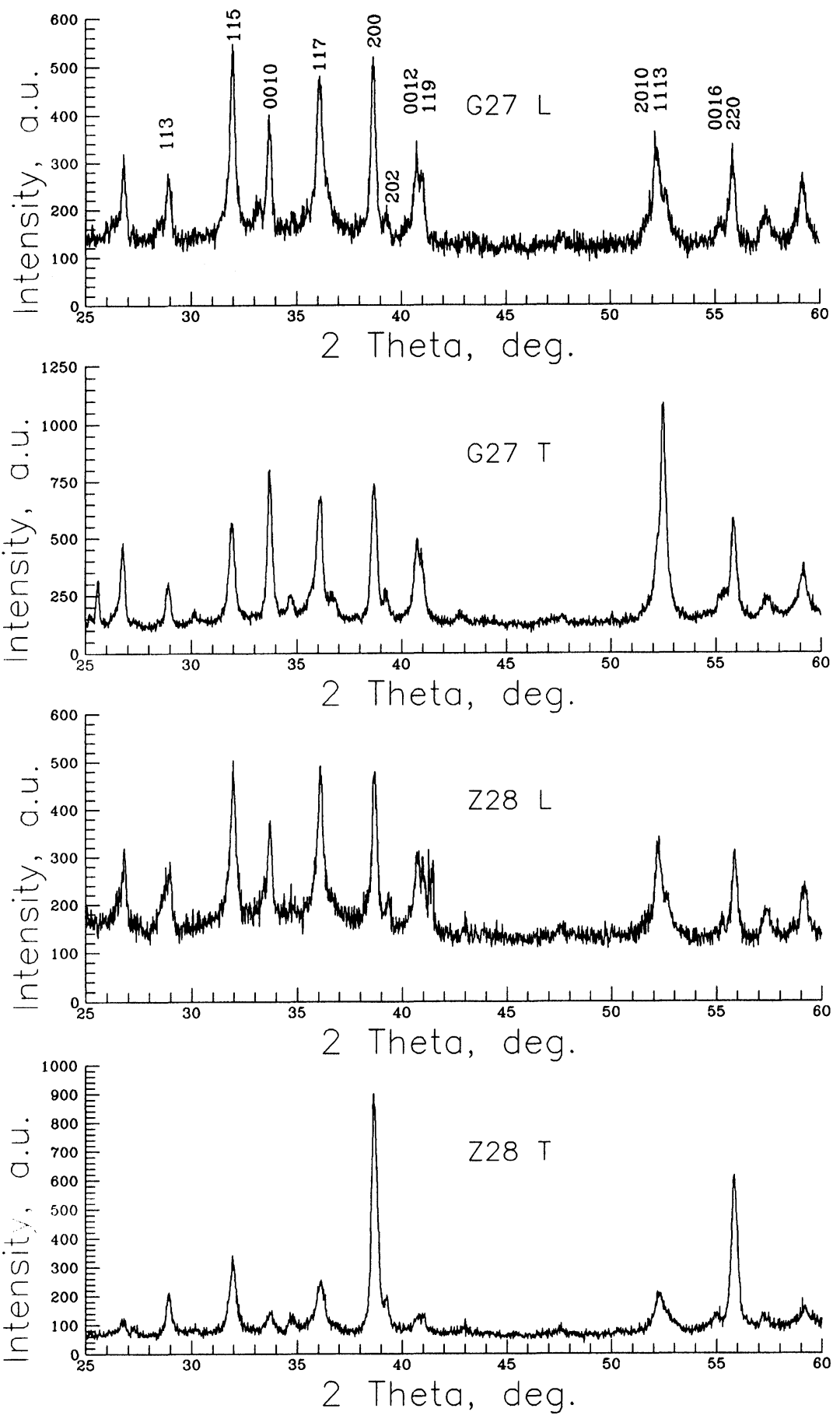

Figure $2 \mathrm{X}$-ray spectra for $T$ and $L$ cross-sections of the samples $G 27$ and $Z 28$. 


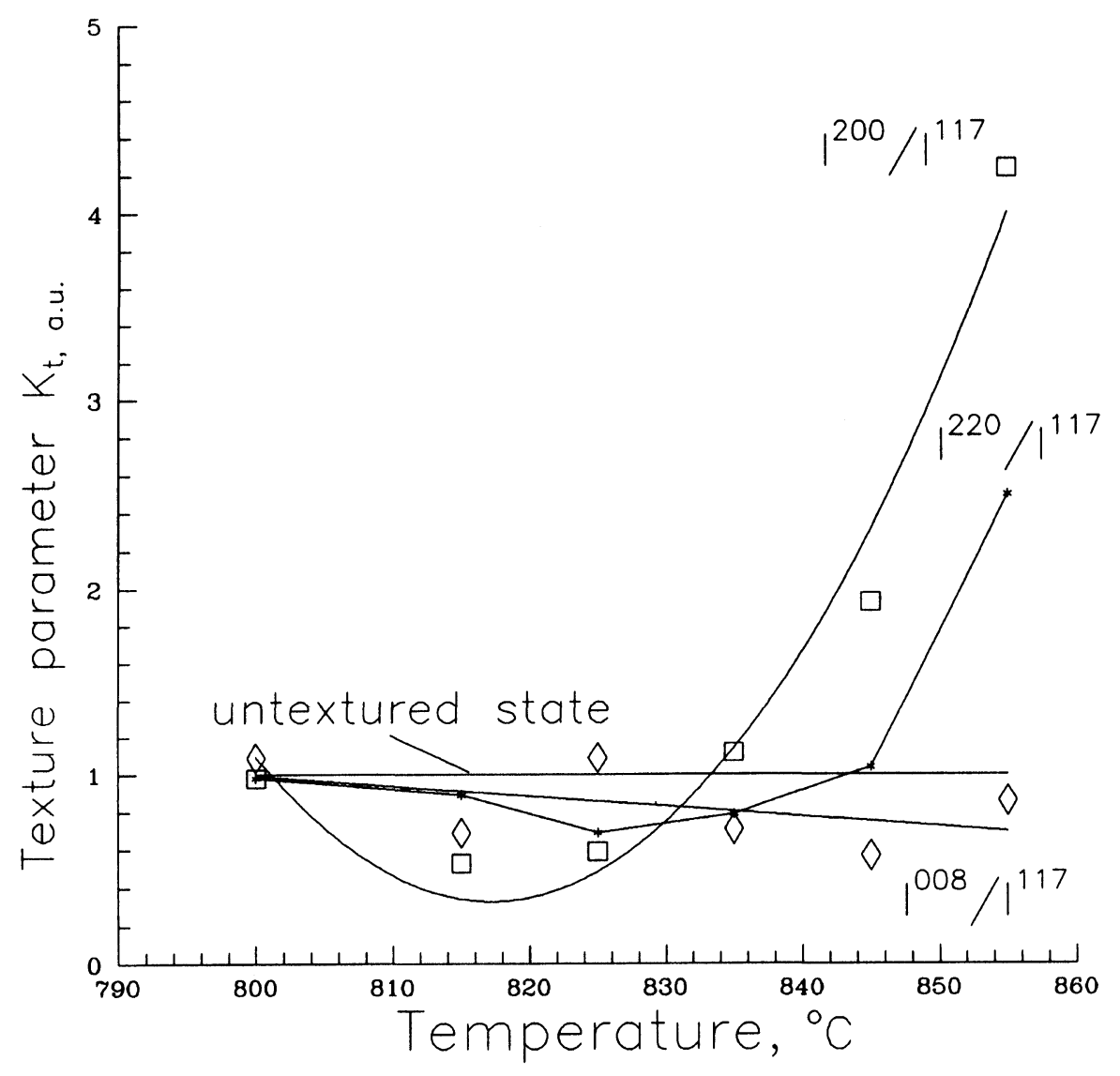

Figure 3 Peak zone temperature dependence on texture degree for $G$-series.

not essentially influence the half-width of the texture maximum (001) of the 2212 phase in accordance with following considerations:

- the content of the 2201 phase in the sample does not exceed 20\%;

- the (115) pole of 2201 is $53^{\circ}$ distant from the (001) pole, so the (115) line contribution to the intensity can be supposed to be constant within the inclination angle $0-20^{\circ}$;

- type and degree of the texture are believed to be the same in the 2201 and 2212 phase in two-phase samples (see, for example ${ }^{8}$ ), so the texture maximum of this phase is characterized by the same half-width.

DPF for the samples $Z 7$ and $Z 21$ are shown in Figure 5. For comparison this figure also shows DPF (001) for tapes manufactured by the oxide-powder-in-tube (OPIT) method after partial melt treatment ${ }^{9}$. Composite Bi2212-Ag tapes exhibit rather simple texture - (001) planes are stacked preferentially along tape surface. This texture is characterized by a single texture component with a compact round maximum in the center of DPF (001). DPF maximum of zone treated samples has a strip like shape 

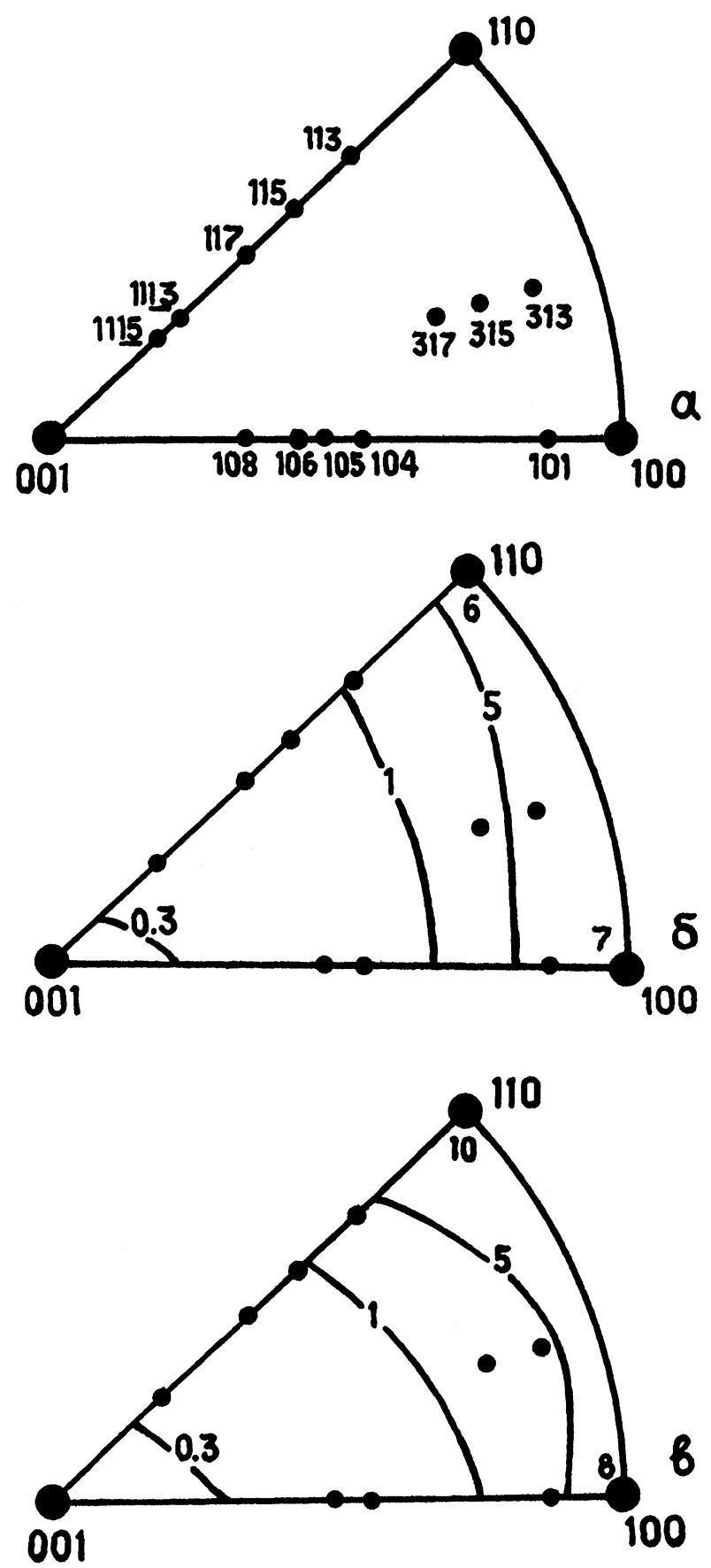

Figure 4 Gnomostereographic projection of Bi2212 phase (a) and inverse pole figures for $G 26$ and Z28 samples (b, c). 


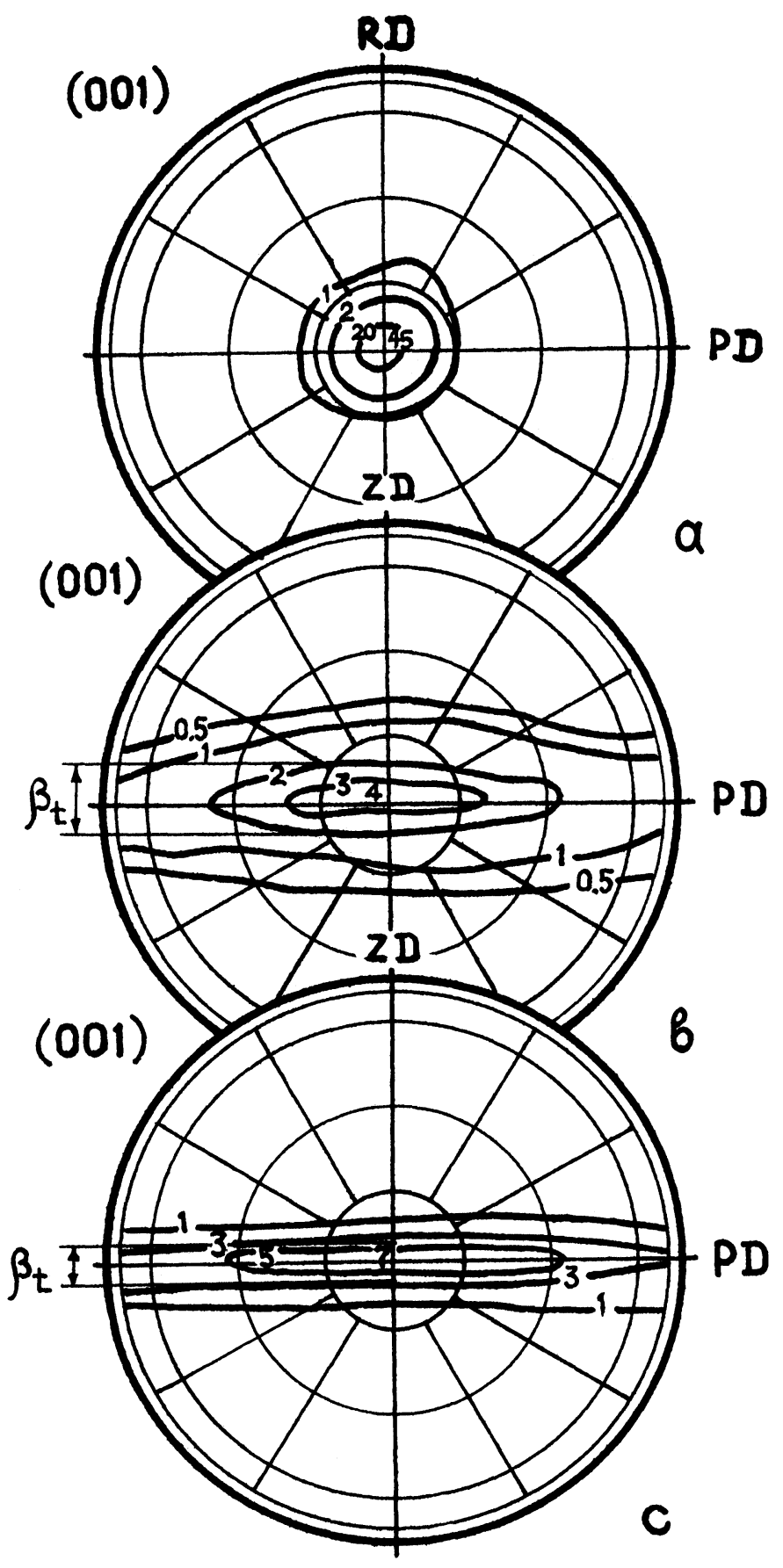

Figure 5 Direct pole figures (001) for $\mathrm{Bi}(2212)-\mathrm{Ag}$ tape rolling plane (a) and for $L$ section of $Z 21$ (b) and $Z 7$ (c) samples. (RD - rolling direction, PD - perpendicular direction, ZD - zone moving direction). 
as it is seen from Figure 5. This indicates that the crystallographic planes (001) are stacked predominantly along the rode axis, but the (001) plane normals are oriented arbitrarily in the directions perpendicular to the rode axis.

The half width $\beta_{t}$ of the texture maximum in the cross section through the rode axis should be used as a parameter of the texture state. The parameter $\beta_{t}$ is $20^{\circ}$ for $Z 7$ and $15^{\circ}$ for $Z 21$ (Figure 5).

We consider that the proposed parameter $\beta_{t}$ is the most correct value for the semiquantitative estimation of the texture degree for such texture type. The poles (100) and (110) of the transverse $T$ cross section can be used only for revealing of the texture presence or absence. So any crystallography direction (HNO) can coincide with the $T$-normal if the (001) planes are stacked perpendicular to the $L$ direction, hence the width and height of the texture maximum (100) and (110) of the corresponding DPF can have different values for the same DPF (001) in $L$ cross section. That is why these (100) or (110) DPF of the $T$ cross section should be used only for subsidiary characterization of the texture state of the investigated samples.

\section{TEXTURE FORMATION DURING ZONE MELTING PROCESS}

During zone melting the following processes concerning the sample morphology could occur: phase transition $2201 \longrightarrow \longrightarrow 2221$; partial melting of grain boundaries; growth of new grains from the melt; recrystallization and so on. From the data obtained we conclude that for strong texture formation the following treatment parameters are favourable: the highest temperature $\left(>850^{\circ} \mathrm{C}\right)$ and the lowest zone velocity $(<12 \mathrm{~mm} / \mathrm{h}$ ).

Earlier we have developed a model of texture formation in a quasi-two-dimensional volume during partial melt technology for $\mathrm{Bi}(2212)-\mathrm{Ag}$ composites ${ }^{9}$. In the present work we tried to elucidate the features of texture formation for zone and gradient methods. From the beginning, for the sake of simplicity, we suppose that only a longitudinal temperature gradient exists (that is we exclude effects of radial temperature distribution - quasi one dimensional case). This condition is realized if the rod diameter is not too large or the zone velocity is not too fast.

It is known that anisotropy is inherent to the process of HTSC-ceramic grain growth from the melt. Estimations obtained from the single crystal habitus show that the growth rate in the (001) plane exceeds the growth rate along the (001) direction over 2 orders of magnitude. Let us denote the growth rate in the (001) plane as $V_{\max }$ and the growth rate in the (100) plane as $V_{\text {min }}$. Let us consider the texture formation process during zone melting. Nuclei with arbitrary orientation may appear in the initial stage. If the zone velocity $R$ is too high $\left(R>V_{\max }\right)$ rapid crystallization takes place and new randomly oriented crystallites are arising in the region through which the zone has been moved. Thus crystallographic texture isn't formed in the sample.

Strong texture will be formed if $R$ doesn't exceed $V_{\max }$. When the zone is moving with $V_{\min }<R<V_{\max }$ all nuclei with the plane (001) parallel to the zone moving direction (or close to this orientation) will grow continuously during zone moving, they "are caught by a zone. "For unfavorably oriented grains the crystallization surface lags behind the zone front, and crystallization terminates. New random oriented grains appear and only favorably oriented grains will be selected by the above-mentioned mechanism. Soon the solidification front will contain predominantly grains with the (001) plane parallel to the $L$ direction only and a strong texture will be formed. Finally, if $R$ is too small $\left(R<V_{\text {min }}\right)$ the growth anistrophy will not cause any effect on the solidification process (at this mode samples with large grains with arbitrary orientation can appear). 
Thus an optimum zone velocity $V_{\min }<R<V_{\max }$ exists for perfect texture formation. It should be noted that the above-mentioned mechanism takes place only in the case of zone melting.

\section{CONCLUSION}

X-ray diffraction analysis of gradient and zone melted samples was carried out.

Texture analysis procedure is developed and the texture state of zone and gradient treated samples is described. The half-width of the texture maximum in the polar direction determines the transport properties of the investigated samples.

A texture formation mechanism is described for the studied samples. It is bases on the anisotrophy of HTSC crystal growth. In the frameworks of the proposed model factors favorable for texture formation were revealed: increasing the zone temperature and slowing down the zone velocity.

\section{Acknowledgements}

Authors express their deep gratitude to Prof. E. Yu. Klimenko and Dr. V. S. Kruglov for helpful discussion and continuing attention to the work. We thank Dr. I. V. Zakharchenko for X-ray data processing procedures and useful discussion.

This work is supported by Scientific Council on High Tc Problems and was performed within the project NO 92023 of the Russian Federation Program "High Tc Superconductivity."

\section{References}

1. Tenbrink, J., Wilhelm, M., Heine, K. and Krauth, H. (1991). Development of high-Tc superconductor wires for magnet applications. IEEE Transactions on Magnetics, Vol. 27, No. 2, March, 1239-1246.

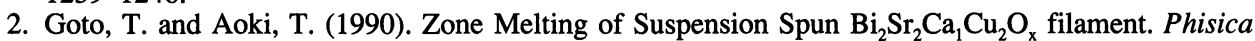
$C, 170,427-430$.

3. Balbashov, A. M., Karabashev, S. G., Kamarov, A. O., Nigmatulin, A. S., Voronkov, S. A., Kamarkov, D. A., Moshchalkov, V. V. and Zhukov, A. A. (1993). Critical current density and morphology of $\mathrm{Bi}_{2} \mathrm{Sr}_{2} \mathrm{CaCu}_{2} \mathrm{O}_{8+\mathrm{x}}$. Fhase Transitions, Vol. 41, 53-60.

4. Antipova, E. V., Bratukhin, P. V., Evstigneev, V. V., Zheleznyakov, V. D., Zakharchenko, I. V., IIyukhin, Yu. V., Khlebova, N. E., Shavkin, S. V. and Shikov, A. K. (1989). Superconductivity: Physics, Chemistry, Technique, Vol. 2, 135-139.

5. Torh, Y., Kudai, H., Takei, H. and Tada, K. (1990). Preparation of Ag-Sheathed (TI, Bi)-CaSr-Cu-O Superconducting Wire. Jap. J. of Appl. Phys., Vol. 29, No. 6, L952-L954.

6. Flukiger, R., Grat, T., Decroux, M., Groth, C. and Yamada, Y. (1991). Critical Currents in Ag Sheathed Tapes of the 2223-phase in ( $\mathrm{Bi}, \mathrm{Pb})-\mathrm{Sr}-\mathrm{Ca}-\mathrm{Cu}-\mathrm{O}$. IEEE Trans. on Magn., Vol. 27, No. 2, 1258-1263.

7. Rusakov, A. A. (1977). “Roentgenography of Metals" (Atomizdat), p. 479.

8. Perlovich, Yu. A., Isaenkova, M. G., Nikulin, A. D., Shikov, A. K., Kalinin, N. B. and Gorshkov, T. P. (1992). Superconductivity: Physics, Chemistry, Technique, Vol. 5, 748-752 (in Russian).

9. Aksenova, T. D., Bratukhin, P. V., Shavkin, S. V., Melnikov, V. L., Antipova, E. V., Khlebova, N. E. and Shikov, A. K. (1993). Texture formation in $\mathrm{Bi}_{2} \mathrm{Sr}_{2} \mathrm{Ca}_{1} \mathrm{Cu}_{2} \mathrm{O}_{\mathrm{x}} / \mathrm{Ag}$ Tapes Prepared by partial melt process. Phisica $C, 205,271-279$. 